\title{
Nature, structure, and properties of asbestos cement dust
}

\author{
J BAETEN, J HELSEN, AND A DERUYTTERE \\ From the Department Metaalkunde, Katholieke Universiteit, Leuven, Belgium
}

ABSTRACT Total dust samples produced by machining three commercial asbestos-cement products (autoclaved sheet, non-autoclaved sheet, pipe) were examined for their dimensional, surface, and physicochemical characteristics. Microscopic inspection of dust fractions with different settling characteristics in air allowed determination of the simple dimensional features that apply to respirable fibres-that is, the true diameter, length, and aspect ratio and the coil diameter, coil length, and coil aspect ratio. The respirable fraction as a percentage of the total dust varied with the type of machined product: $8.5 \%$ for non-autoclaved sheet, $10.5 \%$ for autoclaved sheet, and $35 \%$ for pipe.

Quantitative x-ray diffraction of different granulometric fractions showed that the asbestos content decreases with fraction size (thus the asbestos content will change with distance from the dust source). Electron microscopic examination of fine dust (aerodynamic diameter $<7 \mu \mathrm{m}$ ) showed that only about $10 \%$ of the inspected particles were optically virgin. From these observations it has been calculated that the threshold limit value of 2 fibres per $\mathrm{cm}^{3}$ of air corresponds to a total dust concentration of $1 \cdot 2,0 \cdot 6$, and $0 \cdot 1 \mathrm{mg} / \mathrm{m}^{3}$ and to a maximum admissible respirable dust content of $0 \cdot 1$, 0.06 , and $0.04 \mathrm{mg} / \mathrm{m}^{3}$ for non-autoclaved sheet, autoclaved sheet, and pipe respectively. The surface of optically virgin fibres may still be contaminated by calcium containing particles, as shown by analytical transmission and scanning electron microscope. Dust from the autoclaved product contains fewer calcium coated fibres. The physicochemical behaviour of dust, as shown by dissolution kinetics and adsorption of carcinogens from tobacco smoke, is comparable to the behaviour of cement rather than of pure asbestos. In general, asbestos cement dust differs consistently from pure asbestos. Conclusions, drawn from studies on pure asbestos, cannot be applied as such to asbestos cement dust.

At the beginning of this century asbestos fibres were identified as the causative agent in a specific type of lung fibrosis, later named asbestosis. ${ }^{2}$ Research carried out in the 1930s and supported by investigations made in the past 20 years also suggests a relation between inhalation of asbestos and two types of cancer-bronchial carcinoma and mesothelioma. ${ }^{3-5}$

With respect to asbestosis a dose relationship has been established resulting in a threshold limit value (TLV) for asbestos dust concentration in air below which conditions are considered safe. The actual value imposed by the British Asbestos Regulations of 1969 corresponds to a concentration of 2 respirable fibres per $\mathrm{cm}^{3}{ }^{6}$

Received 6 September 1978 Accepted 20 March 1979
About $60 \%$ of world production of asbestos goes into the asbestos cement industry, which therefore is much concerned about the health hazard. As asbestos cement is a product in which asbestos has intimate contact with cement, the question arises whether asbestos fibres from asbestos cement dust are as dangerous to health as pure asbestos fibres. In this context the industrial grade asbestos fibres used in asbestos cement are considered to be pure.?

No generally accepted view exists about which specific properties of the asbestos fibres should be considered dangerous. One requirement that can be imposed is respirability. At least this requirement must also be imposed on asbestos cement dust particles. Another potentially important factor in the health hazard of asbestos cement dust is the purity of its asbestos fibres.

The aim of the present study was to try to answer the question whether or not respirable asbestos 
cement dust particles are physicochemically different from respirable pure asbestos dust.

\section{Samples}

Dust produced by machining the three most important Belgian commercial asbestos-cement products has been sampled in Eternit plants at Kapelle-opden-Bos and Tisselt. The three products chosen are different in composition or manufacturing process, or both: (1) sheet made of chrysotile and cement, not autoclaved (NA-sheet); (2) sheet made of chrysotile, cement, and quartz, autoclaved (A-sheet); and (3) pipe made of chrysotile, crocidolite, and cement, non-autoclaved (pipe).

In every case the total dust has been sampledthat is, the entire dust produced during a specific machining operation on a specific product. Consequently the dust sample has the same chemical composition as the product itself from which it was machined.

The NA-sheet and A-sheet dusts have been sampled from the bags of the dust collectors fitted to sawing machines. The pipe dust has been sampled from the cyclone of a dust collector fitted to a lathe. Representative samples of about $1 \mathrm{~kg}$ have been taken in each case and kept in well-closed plastic bags. Samples have also been taken from the base materials (asbestos and Portland cement P 300) used in the production of each particular product.

\section{Respirability: definition and geometric features}

The respirability of a dust particle is related to its aerodynamic diameter. The aerodynamic diameter of a particle is the equivalent diameter of a sphere of unit density having the same falling velocity in air as the particle in question. ${ }^{8}$ An experimental retention curve, which relates the percentage respired particles with the aerodynamic diameter, was first proposed at the Johannesburg Pneumoconiosis Conference in $1969 .{ }^{9}$ This curve has been generally accepted as deposition curve for dust in the terminal airways of the lungs. ${ }^{10-12}$ The experimental Johannesburg curve fits the following simple parabolic equation

$$
y=100-2 d^{2} a
$$

with $y=$ retention efficiency in percent

$$
\mathrm{d}_{\mathrm{ae}}=\text { aerodynamic diameter in micrometres }
$$

This equation is similar to the one proposed by Timbrell and Eccles. ${ }^{13}$

It is now feasible to calculate the percentage respirable fraction of the total dust if the mathematical expression of the particle size distribution is known. For this purpose the particle size distribution of the three dust samples was experimentally determined. Two devices were used: the air jet mechanical sieve (Alpine, type A320 LS) and the Bahco air elutriator (Delta Neu). The first method gives the cumulative particle size distribution as a function of the nominal sieve aperture in the interval 32 to $250 \mu \mathrm{m}$ and the second technique the cumulative size distribution as a function of the aerodynamic diameter in the aerodynamic interval 7 to $70 \mu \mathrm{m}$. As experimental conversion factors relating sieve results to elutriator results exist, the entire particle size distribution as a function of the aerodynamic diameter can be obtained. By fitting this experimental particle size distribution to common distributionsfor instance, the Gaudin-Schuhmann-distribution, the Rosin-Rammler-Sperling-Benett-distribution, or the logarithmic normal distribution-the mathematical expression of the particle size distribution has proved to be a logarithmic normal distribution, with the analytical expression ${ }^{14-16}$ :

$$
\mathrm{q}\left(\mathrm{d}_{\mathrm{ae}}\right)=\frac{1}{\mathrm{~s} \sqrt{2 \pi}} \cdot \exp \left\{-\frac{1}{2}\left|\frac{\ln \mathrm{d}_{\mathrm{ae}} / \mathrm{d}_{50}}{\mathrm{~s}}\right|^{2}\right\}
$$

where $q\left(d_{a e}\right)=$ fraction of particles with diameter smaller than $\mathrm{d}_{\mathrm{ae}}$

s $\quad=$ standard deviation

$\mathrm{d}_{\mathrm{ae}}=$ aerodynamic diameter

$\mathrm{d}_{50}=$ geometric mean aerodynamic diameter (median).

The distribution is completely characterised by the values $s$ and $d_{50}$. Table 1 gives the median value of the aerodynamic diameter and the standard deviation for the dust from each product. The correlation coefficient of Pearson is also given.

By combining the mathematical expression of the logarithmic normal distribution with the mathe-

\begin{tabular}{|c|c|c|c|c|}
\hline \multirow[t]{2}{*}{ Product } & \multicolumn{3}{|c|}{ Logarithmic normal distribution } & \multirow{2}{*}{$\begin{array}{l}\text { Respirable fraction } \\
(\%)\end{array}$} \\
\hline & Median $(\mu m)$ & Standard deviation & Correlation-coefficient & \\
\hline $\begin{array}{l}\text { NA-sheet } \\
\text { A-sheet } \\
\text { Pipe }\end{array}$ & $\begin{array}{l}38 \\
17 \cdot 5 \\
6 \cdot 7\end{array}$ & $\begin{array}{l}1 \cdot 51 \\
1 \cdot 02 \\
1 \cdot 01\end{array}$ & $\begin{array}{l}0.99 \\
0.99 \\
0.97\end{array}$ & $\begin{array}{r}8.5 \\
10.5 \\
35.0\end{array}$ \\
\hline
\end{tabular}

Table 1 Characteristics of granulometry and weight percentage of respirable fraction of non-autoclaved sheet, autoclaved sheet, and pipe 
matical expression of the Johannesburg function, the equation for the calculation of the percentage respirable fraction can be derived:

Percent respirable dust $=$

$\frac{1}{s \sqrt{2 \pi}} \int_{\mathrm{ae}_{1}}^{\mathrm{d}_{\mathrm{ae}_{2}}} \frac{\left(100-2 \mathrm{dae}^{2}\right)}{\mathrm{d}_{\mathrm{ae}}} \times$

$\exp \left\{-\frac{1}{2}\left(\frac{1 \mathrm{nd}_{\mathrm{ae}} / \mathrm{d}_{50}}{\mathrm{~s}}\right)^{2}\right\} \mathrm{d} \mathrm{d} \mathrm{d}_{\mathrm{ae}}$

The numerical integration has been done over the aerodynamic diameter interval

$\mathrm{d}_{\mathrm{ae}_{1}}=0.1 \mu \mathrm{m}$ and $\mathrm{d}_{\mathrm{ae}}=7 \mu \mathrm{m}$. The calculated percentages of respirable dust are also given in table 1. The minimum of the total dust deposition curve in the respiratory system lies between 0.5 and $0.1 \mu \mathrm{m}^{17}$ or at $0.5 \mu \mathrm{m} .{ }^{18}$ The lower value was somewhat arbitrarily taken as the lower integration limit.

The next point is to determine the geometric features of the respirable asbestos fibres-that is, to correlate the aerodynamic diameter and the real fibre size. When this relation is known, simple light microscopy becomes a valuable technique to determine the concentration of respirable fibres in a dust sample. Indeed, by sampling a specific quantity of air through a filter and counting the number of respirable fibres, their concentration can be determined.

The first publications about the relation between real size and aerodynamic diameter are from Timbrell $^{8}$ and Stöber et al. ${ }^{19}$ Both these authors selected fibres that were straight cylinders and free from adhering particles, but even pure industrial asbestos contains only a small percentage of such ideal fibres.

To overcome these limitations, respirable pure asbestos fibres, both of chrysotile and crocidolite, were geometrically characterised by transmission electron microscopy (Philips EM 300 microscope).

Asbestos fibres with an aerodynamic diameter smaller than $7 \mu \mathrm{m}$ were collected on electronmicroscope grids placed in an air sedimentation column that had been designed for this purpose (fig 1). The electron-microscope grids were first covered with a thin Formvar film.

The column used was similar to that of the micromerograph. ${ }^{20}$ It was well insulated and installed in a room subjected to only small temperature changes. Although the sedimentation itself was possibly perturbed by small convection currents, the deposits obtained appeared well distributed over a large area. Loose overlap of particles could usually be distinguished in the microscope after carbon shadowing of the sample. The results were reproducible.

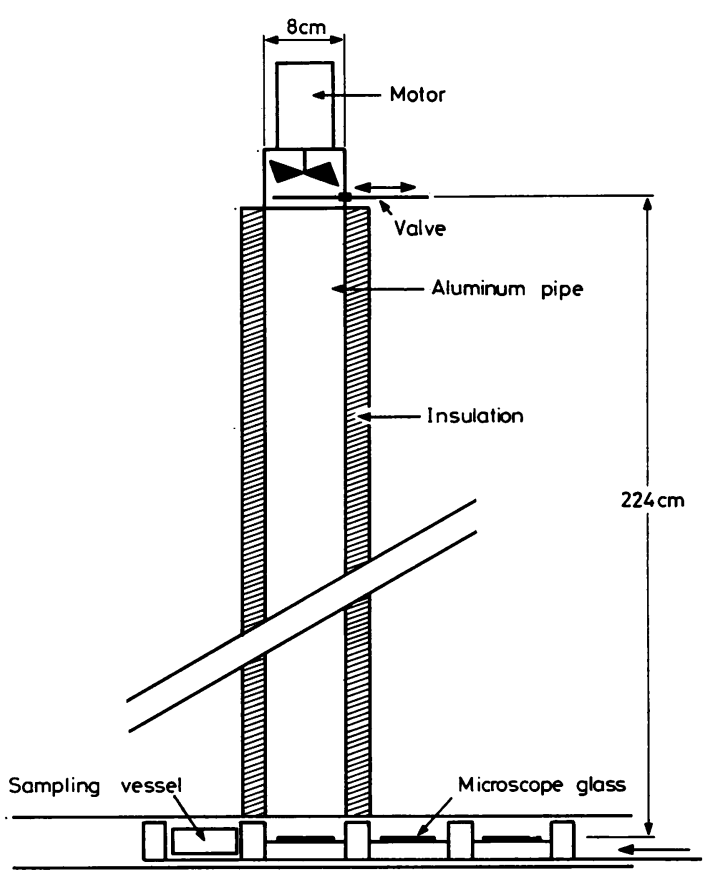

Fig 1 Air sedimentation column.

The characterisation was made using six geometrical measurements. Their common definitions are (Timbrell, ${ }^{21}$ and Gibbs et $a^{22}$ ):

true diameter $\mathrm{d}$ : the diameter of a fibre excluding particles attached to it

coil diameter $d_{c}$ : the maximum fibre diameter including attached particles

true length 1: the length of a fibre after straightening

coil length $1_{c}$ : the length of a fibre as it appears aspect ratio $r$ : the true length to true diameter ratio coil aspect ratio $r_{c}$ : the coil length to coil diameter ratio.

A dust particle was considered to be a fibre when its aspect ratio was larger than 3 . As the above concept of true diameter is not easy to handle, it has been specified as follows: the true diameter is the diameter of a fibre, excluding attached particles, but supposing that it is compressed in the transverse direction so as to bring the fibres of a given bundle close to one another.

Each of the above geometrical measurements followed the logarithmic normal distribution law. No significant difference was found between true length and coil length but significant differences were found between true diameter and coil diameter. 
Therefore, it appears possible to define respirable size in terms of simple geometrical measurements. If the distribution of each measurement is cut off at the median value plus two times the standard deviation $(97.7 \%$ of the measurements are below that limit), the following was found for the specific types of asbestos concerned:

A respirable chrysotile fibre has a true diameter below $3.1 \mu \mathrm{m}$, a maximum true length of $29.5 \mu \mathrm{m}$, an aspect ratio below 40 , a coil diameter below $14.5 \mu \mathrm{m}$, a coil length below $24 \mu \mathrm{m}$, and a maximum coil aspect ratio of $\mathbf{1 8 \cdot 2}$.

A respirable crocidolite fibre has a true diameter below $1.8 \mu \mathrm{m}$, a maximum true length of $28.5 \mu \mathrm{m}$, an aspect ratio below 53.5, a coil diameter below $9.2 \mu \mathrm{m}$, a coil length below $22 \mu \mathrm{m}$, and a maximum coil aspect ratio of 19 .

Evidently these results are only valid for the asbestos types considered. It seems reasonable, however, to assume that the results for asbestos from other origins will have the same order of magnitude. So, by fitting the dimensions of a given fibre to these criteria, it can be decided whether this fibre is respirable or not.

In this way only the geometrical requirements for a fibre to be respirable have been determined. These criteria have been established for fibres with aerodynamic diameters below $7 \mu \mathrm{m}$, but the probability that such fibres are actually respired is given by the Johannesburg curve.

\section{Purity of asbestos fibres in asbestos cement dust}

From transmission electron microscopy we defined somewhat arbitrarily optically pure asbestos fibres as fibres with attached particles of a size smaller than the true diameter. For both industrial asbestos types studied more than $80 \%$ of the fibres fit this definition.

The fine fraction of asbestos cement dust-that is, the fraction with an aerodynamic diameter below 7 $\mu \mathrm{m}$ - has been studied by transmission electron microscopy and the relative quantities of optically pure asbestos fibres, of asbestos cement particles, and of cement particles have been determined (table 2).

By means of these results it is possible to calculate the maximum admissible concentration of total dust in $\mathrm{mg} / \mathrm{m}^{3}$ corresponding to the threshold limit value of 2 fibres per $\mathrm{cm}^{3}$. After determining the equivalent diameter relating number percentages to weight percentages the results in table 3 have been obtained. The maximum admissible concentration of respirable dust is also given in this table. Full details of these calculations are given by Baeten. ${ }^{23}$ If only the fibres that meet the British Asbestos
Table 2 Characteristics of asbestos cement dust of respirable size $\left(d_{a e}<7 \mu \mathrm{m}\right)$

\begin{tabular}{lccc}
\hline $\begin{array}{l}\text { No. of } \\
\text { particles }\end{array}$ & \multicolumn{2}{l}{ Product } & \\
\cline { 2 - 4 } & NA-sheet & A-sheet & Pipe \\
\hline $\begin{array}{l}\text { Asbestos } \\
(\%)\end{array}$ & 6 & 11 & 10 \\
$\begin{array}{l}\text { Cement } \\
(\%)\end{array}$ & 56 & 65 & 58 \\
$\begin{array}{l}\text { Astestos cement } \\
(\%)\end{array}$ & 38 & 24 & 32 \\
Total & 368 & 307 & 259 \\
\hline
\end{tabular}

Table 3 MAC-values of total and respirable asbestos cement dust if optically pure fibres are considered

\begin{tabular}{lll}
\hline Product & $\begin{array}{l}\text { Total dust concentration } \\
\mathrm{mg} / \mathrm{m}^{3}\end{array}$ & $\begin{array}{l}\text { Respirable dust } \\
\text { concentration } \\
\mathrm{mg} / \mathrm{m}^{3}\end{array}$ \\
\hline NA-sheet & $1 \cdot 2$ & $0 \cdot 10$ \\
A-sheet & 0.6 & 0.06 \\
Pipe & 0.1 & 0.04 \\
\hline
\end{tabular}

Table $4 \quad M A C$-values of total and respirable asbestos cement dust if Asbestos Regulations requirements are taken into account

\begin{tabular}{lll}
\hline Product & $\begin{array}{l}\text { Total dust concentration } \\
m g / m^{3}\end{array}$ & $\begin{array}{l}\text { Respirable dust } \\
\text { concentration } \\
m g / m^{3}\end{array}$ \\
\hline NA-sheet & 24 & 2 \\
A-sheet & 10 & 1 \\
Pipe & 3 & 1 \\
\hline
\end{tabular}

Regulations requirements are considered (a length greater than $5 \mu \mathrm{m}$ ) then the maximum admissible concentration increases (table 4). These results appear to correspond well with the experimental results generally obtained with portable equipment worn by workers in the plant (Johns Manville, private communication, 1978).

For the products under study the nominal asbestos concentration never exceeded $15 \%$. It is evident that these results should not be extrapolated to products with much higher nominal asbestos concentrations, such as some specific asbestos insulation products.

Up to now, the optical purity of a fibre has been taken into account. The chemical purity, however, should also be considered.

An exploratory investigation has been made by means of qualitative and quantitative $x$-ray diffractometry, using a Philips x-ray diffractometer with rotating specimen holder. The $\mathrm{Cu}$-radiation was generated at $34 \mathrm{KV}$ and $20 \mathrm{~mA}$ and was nickel filtered.

Specimens have been prepared by pressing mix- 
tures of different granulometric asbestos-cement dust fractions with aluminium into pellets of $13 \mathrm{~mm}$ diameter. The spherical aluminium powder was added as an internal standard. ${ }^{24}$

The results show clearly that the asbestos as such is present in the dust. The other components detected are hydrated cement compounds. No other compounds have been identified in detectable concentration.

Quantitative x-ray diffractometry showed that when an asbestos cement dust is divided in granulometric fractions, the lower the chrysotile and the crocidolite contents of a dust fraction the smaller the size of the dust in the fraction. This is clearly shown by fig 2 . The study also showed a demixing of the cement components over the different granulometric fractions. It is an important fact that the composition of the dust changes with the distance from its dust source.

X-ray diffractometry allows identification of crystalline compounds but does not locate them. For this purpose analytical microscopes can be used.

Electron-microscopic techniques allow the investigation of the optical and analytical features of individual dust particles. A scanning electron microscope (SEM) equipped with an energy dispersive $\mathrm{x}$-ray spectrometer was used. Different modes of operation are possible. For the present study the

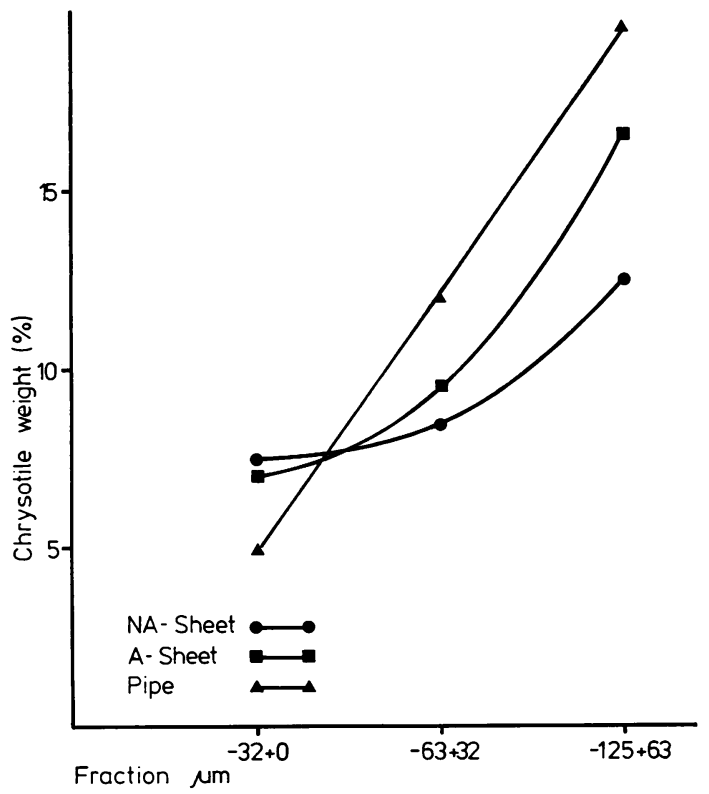

Fig 2 Chrysotile concentration as a function of the asbestos cement dust fraction.

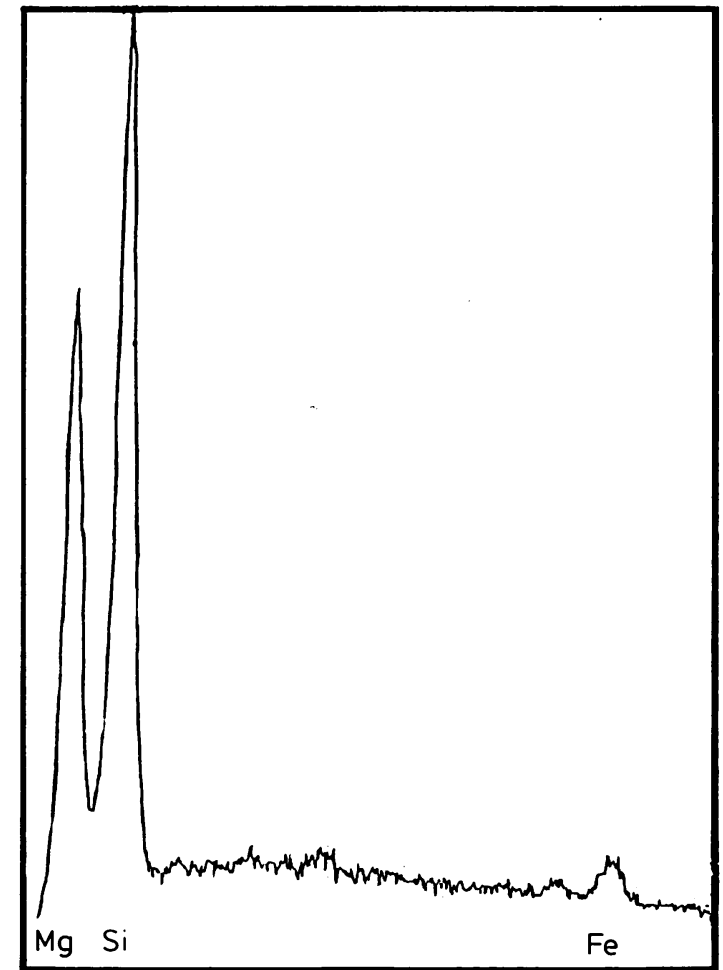

Fig $3 X$-ray spectrum of a pure chrysotile fibre.

spot analysis and x-ray image mode of operation gave analytical information about an area of 3-4 $\mu \mathrm{m}$ in diameter and a depth depending on the composition.

Specimens have been prepared by dispersing either asbestos or asbestos cement in n-hexane and collecting on a membrane filter with $0.2 \mu \mathrm{m}$ pore size. Subsequently the dispersion was coated with a thin carbon layer.

The x-ray spectra obtained with the SEM operating in the spot analysis mode often showed a calcium peak at the given magnification for apparently pure asbestos fibres from asbestos cement dust. On the contrary the presence of calcium has never been detected on pure asbestos fibres. Two examples of $x$-ray spectra are shown in figs 3 and 4 . To make sure that the detected calcium peak originated from the fibre or its surface and not from neighbouring cement particles, $x$-ray images were taken (figs 5-7). They confirmed that the fibres are covered with some calcium containing product. By analysing the effect of this coating on the $\mathrm{Mg} / \mathrm{Si}$ (chrysotile) and $\mathrm{Fe} / \mathrm{Si}$ (crocidolite) peak height ratios (PHR), an attempt was made to get more information about 


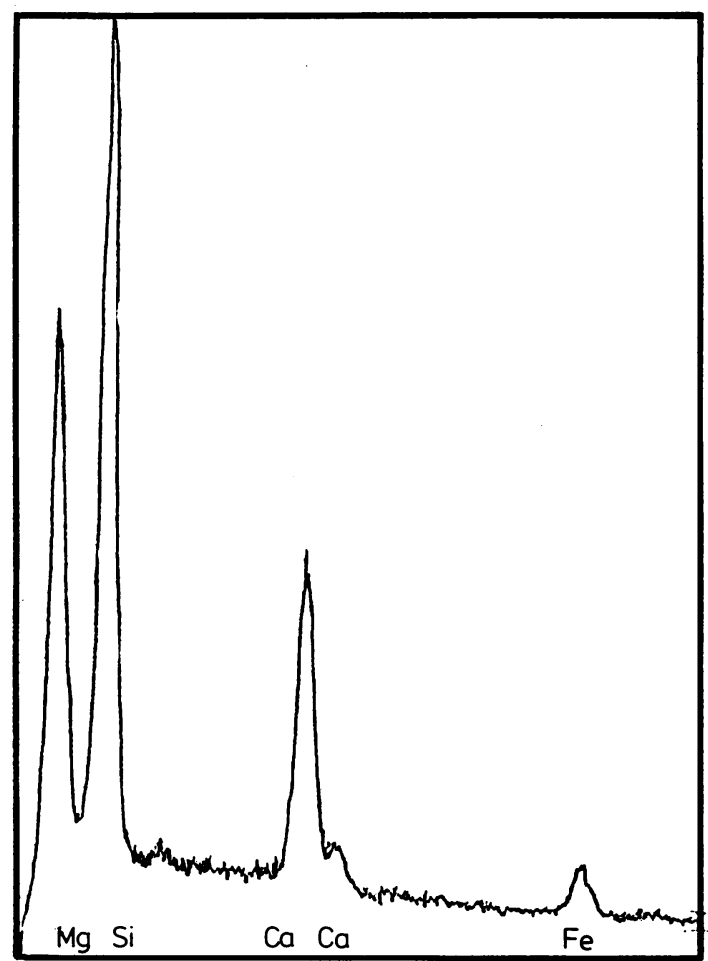

Fig $4 X$-ray spectrum of a chrysotile fibre in NAsheet.

the nature of the calcium containing coating - that is, to find out whether it is a silicate or a non-silicate. Table 5 gives the PHR values both for pure asbestos fibres and for fibres found in the asbestos cement products.

The most important factors that affect the peak height ratio of an asbestos fibre are: absorption,
Table 5 Mean peak height ratio (PHR) $\mathrm{Mg} / \mathrm{Si}, \mathrm{Ca} / \mathrm{Si}$, and $\mathrm{Fe} / \mathrm{Si}$ of asbestos from NA-sheet, A-sheet, and pipe

\begin{tabular}{llllll}
\hline Products & \multicolumn{2}{l}{ Chrysotile } & & \multicolumn{2}{l}{ Crocidolite } \\
\cline { 2 - 3 } \cline { 5 - 6 } & $\mathrm{Mg} / \mathrm{Si}$ & $\mathrm{Ca} / \mathrm{Si}$ & & $\mathrm{Fe} / \mathrm{Si}$ & $\mathrm{Ca} / \mathrm{Si}$ \\
\hline Pure & 0.649 & - & 0.636 & - \\
NA-sheet & & & & \\
$-63+32$ & 0.592 & 0.419 & & - \\
-32 & 0.552 & 0.507 & - & - \\
-63 & 0.572 & 0.463 & & \\
A-sheet & & & & \\
$-63+32$ & 0.544 & 0.176 & - & - \\
-32 & 0.486 & 0.331 & - & - \\
-63 & 0.515 & 0.253 & & \\
Pipe & & & & \\
$-63+32$ & 0.525 & 0.476 & 0.564 & 0.476 \\
-32 & 0.442 & 0.360 & 0.580 & 0.484 \\
-63 & 0.484 & 0.418 & 0.572 & 0.480 \\
\hline
\end{tabular}

secondary fluorescence, and relative element concentration. The atomic number correction has been neglected because the mean atomic number varies only between 10 and 16 .

The effect of fluorescence has been calculated by the method of Wittry and that of absorption by the method of Philibert (both methods described in Colby ${ }^{25}$ ). By substitution it becomes feasible to derive an expression for the relation between the PHR of pure asbestos and the PHR of asbestos from asbestos cement dust.

By supposing different hypothetical calcium containing coatings on the pure asbestos fibres it was determined how the PHR of table 5 for asbestos from asbestos cement dust could be reached. It was always assumed that the hypothetical coating corresponds with $20 \%$ of the excited volume-the volume from which fluorescence information is obtained. The calculation showed that silicon containing calcium compounds form the major part of the coating.

It is impossible, however, to conclude from the SEM study whether the asbestos fibres are coated

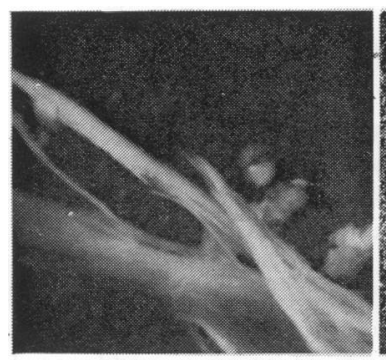

$1350 x$

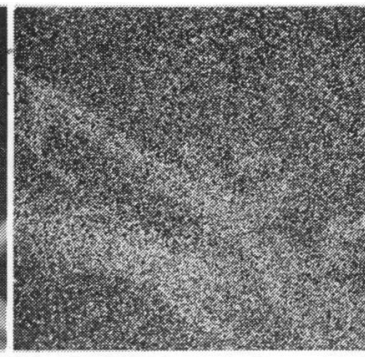

$\mathrm{Si}$

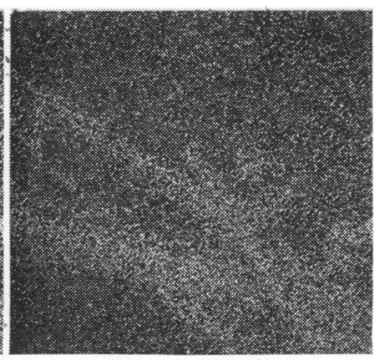

$\mathrm{Mg}$

Fig 5 Electron and x-ray images of pure asbestos fibres. 


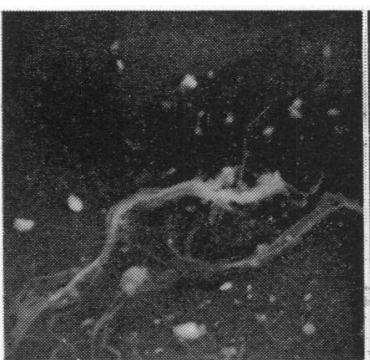

$350 x$

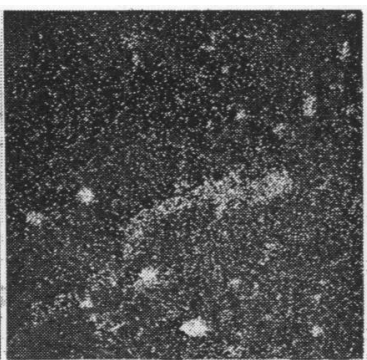

$\mathrm{Ca}$

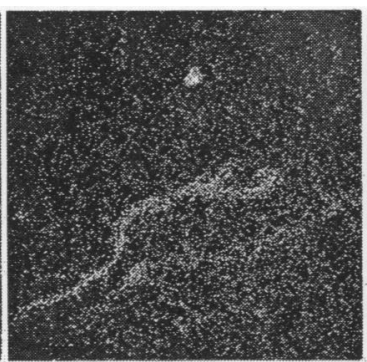

$\mathrm{Si}$

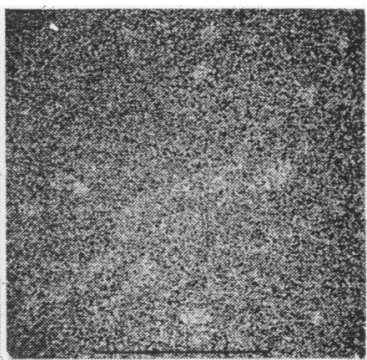

$\mathrm{Mg}$

Fig 6 Electron and $x$-ray images of chrysotile fibres of NA-sheet dust.

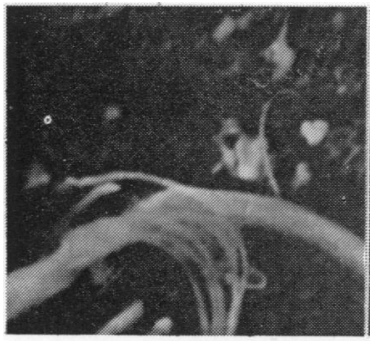

$2250 x$

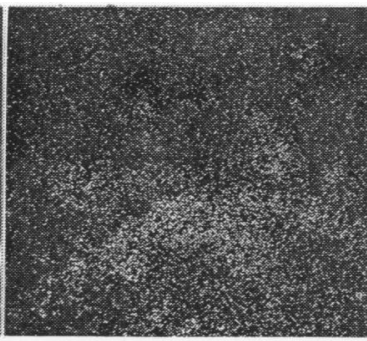

$\mathrm{Ca}$

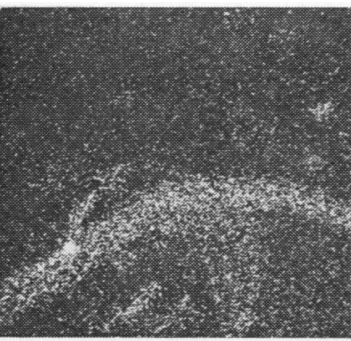

Si

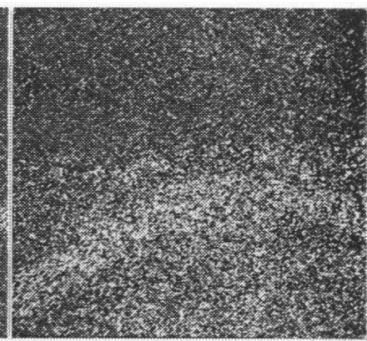

$\mathrm{Mg}$

Fig 7 Electron and $x$-ray images of chrysotile fibres of pipe dust.

with a continuous calcium containing layer or with discrete particles. Indeed, when the particles are separated from each other by a distance less than 3-4 $\mu \mathrm{m}$, they will not be distinguished as individual particles but appear to belong to a continuous layer.

This question has been further investigated by analytical transmission electron microscopy and by electron diffraction, using a Philips EM 300 microscope equipped with an X-ray energy dispersive spectrometer. A higher magnification is then possible in comparison to the SEM. Moreover, the analytical information is exclusively produced by the sample area covered by the incident electron beam. The beam section is shown by the circles drawn on the photograph in fig 8 (encircled contamination spots). The specimens have been prepared by air sedimentation. Figure 8 shows the spectra of areas 1 and 2 of a fibre. For area 1 there is no calcium peak and no apparent protuberance, whereas for area 2, a small calcium peak appears in the X-ray spectrum, corresponding to the small attached particles (about $0.1 \mu \mathrm{m}$ in size). The same observations have been made on many fibres. The electron beam diameter was about $0.6 \mu \mathrm{m}$. The conclusion is that the $\mathrm{x}$-ray calcium pictures of asbestos fibres in asbestos cement dust obtained with
SEM probably correspond to very fine calcium containing particles lying only a few microns apart. The size of these particles may be in the range $0 \cdot 1$ $0.2 \mu \mathrm{m}$.

The transmission electron microscope offers also the possibility of obtaining an electron diffraction pattern of an area $1 \mu \mathrm{m}^{2}$ in size. The electron diffraction patterns of attached particles correspond with different calcium compounds. This shows that different types of calcium compounds are responsible for the calcium x-ray images obtained with the SEM.

\section{Some physicochemical tests}

To characterise the fibre surface further, its physicochemical behaviour has been studied. Two different ways have been chosen: the protolysis of the fibres and the study of its adsorption properties.

\section{KINETICS}

The kinetic study of protolysis has been performed on the $-32 \mu \mathrm{m}$ chrysotile and asbestos cement dust fractions obtained by sieving. The pHs used were 8 and 5 and the temperature $37^{\circ} \mathrm{C}$. During protolysis the $\mathrm{HCl}$-consumption ( $\mathrm{HCl}$ added to keep the $\mathrm{pH}$ 


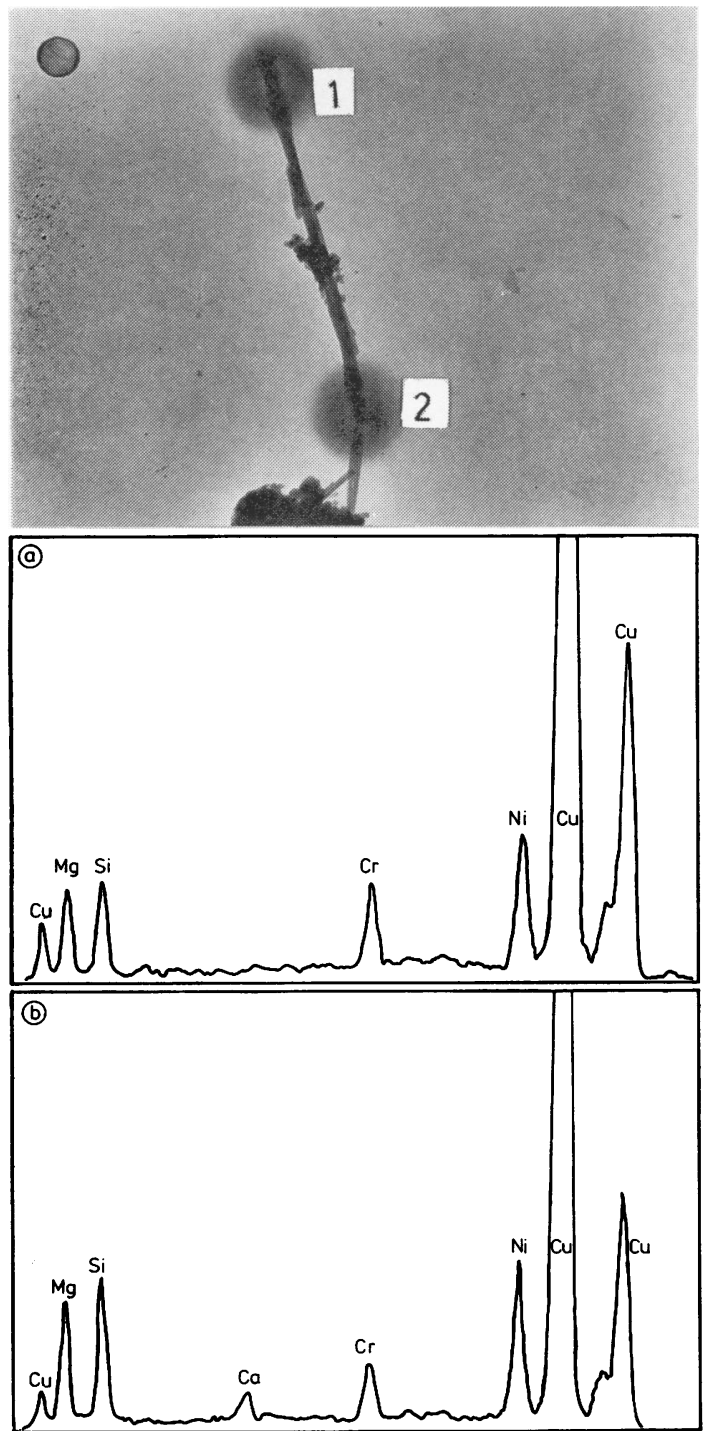

Fig $8 X$-ray spectrum of a chrysotile fibre in NAsheet (a) print 1, (b) print 2.

constant) and the concentration of $\mathrm{Mg}$ - and $\mathrm{Ca}$-ions have been followed as a function of time. The cation analysis has been done with atomic absorption spectrophotometry. The kinetics of the pure chrysotile protolysis appears to be diffusion controlled as shown by the Janders equation in reduced coordinates (fig $\mathbf{9 2 6}^{26}$ :

$(1-\alpha)^{1 / 2}=-0.02\left(\frac{t}{t_{0.04}}\right)^{1 / 2}+1$

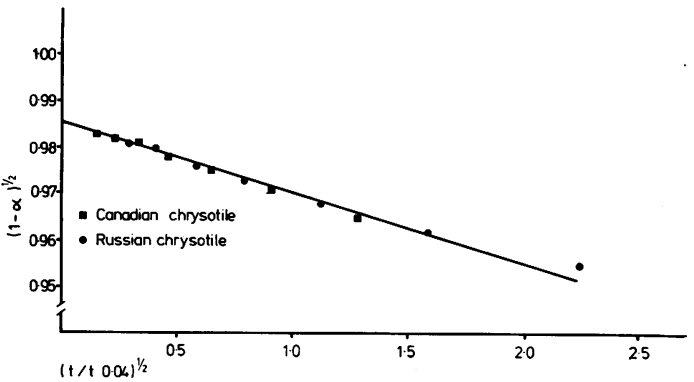

Fig 9 Jander's equation in reduced coordinates.

where: $\alpha=$ degree of protolysis

$$
\begin{aligned}
& t=\text { time } \\
& t_{0.04}=\text { time for } a=0.04
\end{aligned}
$$

By comparing the $\mathrm{pH}$-effect on the protolysis kinetics of NA-sheet, A-sheet, and chrysotile dust, it can be concluded that fibres in NA-sheet dust are relatively better covered with hydrated cement than fibres in A-sheet dust. The pH-effect is illustrated in fig 10. It shows that the linear relation that holds for

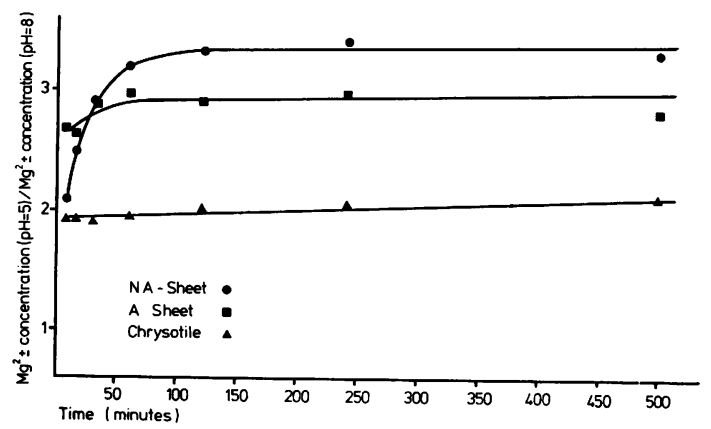

Fig 10 pH-effect on rate of protolysis.

pure chrysotile is sooner attained in A-sheet dust than in NA-sheet dust. This result could be expected if one considers the fact that the number percentage of optically pure fibres is smaller in NA-sheet than in A-sheet (table 2). Moreover, the x-ray image examination with the SEM of A-sheet dust showed a few chemically pure fibres.

It was also found that at $\mathrm{pH}=5,80 \%$ of the cement was dissolved both for NA-sheet dust and for A-sheet dust, whereas at a $\mathrm{pH}=8$ the percentages were respectively 70 and $55 \%$ (after eight hours). It should not be concluded that the asbestos cement aggregates would behave in the same way in the lung fluids. 


\section{ADSORPTION}

Adsorption experiments from solutions of two important carcinogenic agents from tobacco smoke (benzo [a] pyrene and maleic acid hydrazide) have been performed on chrysotile asbestos, on hydrated cement, and on NA-sheet and A-sheet dust. By means of ultraviolet spectrophotometry the adsorption of each carcinogen as a function of its initial concentration in solution has been measured. The benzo [a] pyrene was dissolved in benzene and $\mathrm{n}$-hexane and the maleic acid hydrazide in methanol. Depending on the type of the carcinogen, chrysotile adsorbed more or less than hydrated cement or asbestos cement. In the case of benzo [a] pyrene dissolved in benzene and $\mathrm{n}$-hexane, chrysotile showed to be a stronger adsorbent than hydrated cement or asbestos cement. In the case of maleic acid hydrazide dissolved in methanol the reverse is true. It is important to note that in both cases asbestos cement products, in so far as their adsorption characteristics in the given conditions are concerned, behave very much like pure hydrated cement.

\section{Conclusions}

A definition of the size of respirable fibres in terms of the geometrical measurements of the fibres has been proposed. The present study has shown that the heterogeneous nature of the cement matrix is also found on the surface of the asbestos fibres present in asbestos cement dust. Indeed, electron microscopic study of dust from asbestos cement products showed that the fibres are not covered by a continuous layer of cement or its reaction products. Small calcium containing particles (mainly calcium silicates) are adhering to the surface of the fibres. Fibres, corresponding with the definition of optical purity ( $80 \%$ of the fibres in an industrial asbestos), are not necessarily chemically pure. No quantitative estimation of percentages of chemically pure fibres could be performed.

Quantitative x-ray diffractometry of different dust fractions showed that the composition of the dust is a function of the size fraction.

The degree of coverage of the fibres by cement particles affects the dissolution rate of the fibres.

Asbestos cement particles behave much like cement particles in so far as the adsorption of two carcinogens of different polarity from tobacco smoke is concerned.

Whether asbestos cement dust is as hazardous to health as pure asbestos dust cannot be concluded from the present study. It would, however, be unjustified to apply automatically to asbestos cement every conclusion which is arrived at for pure asbestos.

\section{References}

${ }^{1}$ Auribault M. Observations sur l'hygiène et la sécurité des travailleurs dans les filatures et tissanderies d'amiante. Bull Insp Travail 1906;196.

${ }^{2}$ Murray MH. Statement before the committee in the minutes of evidence, Report of the Departmental Committee on Compensation for Industrial Disease. London: HMSO, 1907:127-8.

${ }^{3}$ Lynch KM, Smith WA. Carcinoma of the lung in abestos-silicosis. Am J Cancer 1935;24:56-64.

${ }^{4}$ Gloyne SR. Squamous carcinoma of lung occurring in asbestosis: two cases. Tubercle 1935;17:5.

${ }^{5}$ Doll R. Mortality from lung cancer in asbestos workers. Brit J Ind Med 1955;12:81-6.

- The Asbestos Regulations. SI No 690. London: HMSO, 1969.

'Insulants and refractories, 1976. Mining Annual Review. London: Mining Journal, 1976:118-9.

${ }^{8}$ Timbrell V. The inhalation of fibrous dust. Ann $N Y$ Acad Sci 1965;132:255-73.

- Proceedings of the Pneumoconiosis Conference, Johannesburg. Shapiro HA, ed. London: Oxford University Press, 1969:619.

10 Jacobson M. Environmental dust survey of bituminous coal-mines in the United States. Proc Int Conf Johannesburg. London: Oxford University Press, 1969:623-7.

11 Schütz A, Coenen W. Feinstaub: Definition-Messerfahren. Staub-Reinhaltung der Luft 1974;34:323-6.

${ }^{12}$ Schütz A. Beurteilung der Gesundheitsgefahren durch mineralische Staube am Arbeitsplatz-Grenzwerte für Quarz und Asbest, Messmethoden. Staub-Reinhaltung der Luft 1975;35:263-6.

${ }^{13}$ Timbrell V, Eccles JD. The respirability of aerosols produced in dentistry. $J$ Dent 1973;2:21-31.

14 Leschonski K, Alex W, Koglin B. Teilchen Groessen Analyse Darstellung und Auswertung von Teilchengroessenserteilungen. Chemie-Ingenieur-Technik 1974; 46:101-6.

${ }^{15}$ Irani R, Callis C. Particle size: measurement, interpretation and application. New York: John Wiley, 1963.

16 Espenscheid WF, Kerker M, Matijevic E. Logarithmic distribution functions for colloidal particles. $J$ Phys Chem 1964;68:3093-7.

${ }^{17}$ Task Group on Lung Dynamics. Deposition and retention models for internal dosimetry of the human respiratory tract. Health Phys 1965;12:173-207.

${ }^{18}$ Desaedeleer GG, Winchester JW. Trace metal analysis of atmospheric aerosol particle size fractions in exhaled human breath. Environ Sci Technol 1975;9:971-2.

19 Stöber W, Flachsbart H, Hochrainer D. Der aerodynamischen Durchmesser von Latexaggregaten und Asbestfadern. Staub-Reinhaltung der Luft 1970;30:277-85.

${ }^{20}$ Eadie FS, Payne RE. The micromerograph. Brit Chem Eng 1956;306-11.

21 Timbrell V. The inhalation of fibres. Proc Int Conf Johannesburg. London: Oxford University Press, 1969:3-9.

${ }^{22}$ Gibbs GW, Hwang CY. Physical parameters of airborne asbestos fibres. Int conf on the chem and phys of asbestos minerals. Universités Laval, Québec, Canada, paper 8.37.

${ }^{23}$ Baeten J. PhD Thesis, Departement Metaalkunde, KU Leuven. 1979.

${ }^{24}$ Cullity BD. Elements of $x$-ray diffraction. London: Addison-Wesley, 1956.

${ }^{25}$ Colby JW. The applicability of theoretically calculated intensity corrections in microprobe analysis. The electron microprobe. New York: Wiley, 1966:95-189.

${ }^{26}$ Habashi F. Principles of extractive metallurgy. Vol I. New York: Gordon and Breach, 1969. 